\title{
¿Referéndum tras denunciar un tratado de derechos humanos?
}

\author{
Editado por/Edited by: Alejandro Borja \\ Recibido/Received: 26/01/2014. Aceptado/Accepted: 15/05/2014 \\ Publicado en línea/Published on Web: 10/09/2014
}

\author{
Víctor Cabezas \\ Universidad San Francisco de Quito, Colegio de Jurisprudencia JUR \\ Diego de Robles y Vía Interoceánica, Quito, Ecuador \\ Correo electrónico:victor.cabezas@estud.usfq.edu.ec
}

\section{Resumen}

Los recientes y recurrentes pronunciamientos del Estado ecuatoriano frente al Sistema Interamericano de Derechos Humanos (SIDH) están basados principalmente en la crítica de las Medidas Cautelares operadas por la Comisión Interamericana de Derechos Humanos (CIDH). Ante este escenario, el Estado ha amenazado con denunciar la Convención Americana de Derechos Humanos (CADH), tratado contenedor del SIDH. Se realizará un análisis acerca de la naturaleza de las medidas cautelares, la pertinencia de un referéndum en caso de que se denuncie la CADH, en virtud del bloque de constitucionalidad, y finalmente se analizará la constitucionalidad de estos actos en conjunto e independientemente.

Palabras clave: Constitución, Bloque de Constitucionalidad, derechos humanos, medidas cautelares.

\section{Abstract}

Ecuador has made public announcements in regard to its will of reforming the Inter-American Human Rights System. The recent declarations by the Ecuadorian State are fundamentally based on opposition to the Inter-American Human Rights Commission's (IAHRC) faculty to execute judicial precautionary measures. If this is not viable, this State has contemplated the idea of denouncing the American Convention on Human Rights (ACHR). An analysis will be developed in relation to the essentials of the precautionary measures and the pertinence of a referendum in the event that the Ecuadorian State decides to denounce the ACHR, basing on the Constitutional Block theory. Finally, the constitutionality of these acts will be analyzed jointly and independently.

Palabras clave: Constitution, Constitutional Block, Human Rights, precautionary measures.

Durante los últimos meses hemos observado una injerencia directa del poder político en uno de los organismos más pertinentes y útiles que han tenido a su disposición los ciudadanos americanos, el Sistema Interamericano de Derechos Humanos (SIDH). Éste representa un marco para la promoción, activismo y protección de los Derechos Humanos en el continente, mientras provee mecanismos para su defensa a través de dos pilares fundamentales: la Comisión Interamericana de Derechos Humanos (CIDH) y la Corte Interamericana de Derechos Humanos (en adelante, Corte IDH). El SIDH se fundamenta, asimismo, en la Declaración Americana de los Derechos y Deberes del Hombre adoptada en 1948, en la carta de la OEA y finalmente en la Convención Americana de Derechos Humanos (CADH) suscrita en 1969 y vigente desde 1978. Tanto la CIDH como la Corte IDH han jugado un papel fundamental en la defensa de los Derechos Humanos a lo largo y ancho del continente, constituyendo un verdadero referente de efectiva tutela de los mismos en regímenes anti-democráticos, de los cuales estuvo plagado el continente especialmente en la segunda mitad del siglo XXI.

Con el advenimiento de la Revolución Ciudadana y la Constitución que se promovió se realizaron cambios estructurales en numerosas instituciones jurídicas (Guzmán, 2010), se reconoció a la naturaleza como sujeto de derechos y se establecieron numerosas garantías constitucionales que pretendían dotar de seguridad y noción de protección indeleble del Estado hacia los ciudadanos (Guzmán, 2010). Sin perjuicio del cúmulo de garantías existentes, el Estado ecuatoriano está muy lejos de estar conformado por un sistema judicial independiente, imparcial y profundamente respetuoso a las libertades civiles y la garantía de derechos.

El Estado Ecuatoriano ha presentado múltiples quejas en relación a la actual operancia del SIDH. En virtud de la relevancia jurídica y política analizaremos uno de los principales argumentos del Estado en relación con este aspecto: La facultad de la CIDH para solicitar que los Estados adopten medidas cautelares. A partir de esta tesis, el Estado ecuatoriano ha iniciado una campaña mediático-política con el fin de lograr reformas profundas en el SIDH e inclusive ha llegado a amenazar con denunciar la Convención Americana en caso de que se haga caso omiso a sus pretensiones. En el presente texto daremos breve lectura a los argumentos jurídicos que fundamentan la inquietud Estatal ante el SIDH. Además analizaremos la medida en la cual la denuncia de un tratado adscrito al bloque de consti- 
tucionalidad ecuatoriano, requeriría la convocatoria a consulta popular en virtud de su carácter evidentemente reformista de los mecanismos de tutela de Derechos Humanos en el Ecuador.

Como se mencionó anteriormente, uno de los principales argumentos del Estado Ecuatoriano en relación a la supuesta disfuncionalidad del SIDH recae sobre las medidas cautelares como atribución de la Comisión. Empezaremos analizando su naturaleza y diremos que las mismas están destinadas a evitar que el tiempo transcurrido en el proceso, afecte intereses y bienes jurídicos superiores y de mayor valía para el individuo y la sociedad en general. Las medidas tienen por objeto evitar que un Estado o una situación determinada causen agravio irreparable a un interés subjetivo, en este último escenario a partir del principio jurídico, universal y tradicionalmente aceptado, del buen derecho del demandante y el peligro de la mora fumus boni iuris e periculum in mora (Correa, 2008). La atribución para solicitar medidas cautelares, se encuentra sustanciada en el artículo 25 del Reglamento de la CIDH, de conformidad con lo descrito en el mismo:

En situaciones de gravedad y urgencia la Comisión podrá, a iniciativa propia o a solicitud de parte, solicitar que un Estado adopte medidas cautelares para prevenir daños irreparables a las personas o al objeto del proceso en conexión con una petición o caso pendiente, así como a personas que se encuentren bajo su jurisdicción, en forma independiente de cualquier petición o caso pendiente. Estas medidas podrán ser de naturaleza colectiva a fin de prevenir un daño irreparable a las personas debido a su vínculo con una organización, grupo o comunidad de personas determinadas o determinables (Medidas Cautelares).

Al tenor de la definición de medidas cautelares que hemos presentado, es claro que su objetivo deóntico es la protección de los Derechos Humanos en situaciones de alto riesgo, en momentos en los cuales se necesitan acciones concretas, directas e inmediatas para evitar lesiones irreparables. Quizás este concepto pueda resultar ambiguo para ciertos lectores. En aras de ejemplificar su aplicación, revisaremos un caso reciente en el cual se evidencia flagrantemente la importancia, utilidad y pertinencia de las medidas cautelares.

El 20 de febrero de 2014, la CIDH solicitó la adopción de medidas cautelares a favor de Daniel Ramos Alfaro de 21 años, cuya vida e integridad personal se encontrarían en grave riesgo en vista que desde el 2 de octubre de 2013 no se conoce su paradero o destino. La solicitud de medidas cautelares alega que Daniel Alfaro habría sido retenido por supuestos miembros de las fuerzas militares mexicanas mientras se dirigía hacia la comunidad de San Martín, luego de dictar clases en la escuela de la comunidad Betania. Dada la naturaleza de la situación denunciada (...). El Estado de México respondió por medio de un informe el 22 de enero de 2014, y la CIDH recibió asimismo información adicional el 1 de febrero de 2014 por parte del solicitante. Tras analizar los alegatos de hecho y de derecho, la Comisión considera que la información demuestra, en principio, que el joven Daniel Ramos se encuentra en una situación de gravedad y urgencia, puesto que sus derechos a la vida y a la integridad personal estarían en grave riesgo, en vista que a la fecha, y transcurridos 141 días desde su desaparición, no se co- nocería su paradero o destino. En consecuencia, de acuerdo con el Artículo 25 del Reglamento de la CIDH, la Comisión solicita al Estado de México que: adopte las medidas necesarias para determinar la situación y el paradero de Daniel Ramos Alfaro, con el propósito de proteger sus derechos a la vida y a la integridad personal, y que se informe sobre las acciones adoptadas a fin de investigar los hechos que dieron lugar a la adopción de la presente medida cautelar (Medidas Cautelares).

La percepción oficial del Estado ecuatoriano, frente a las medidas cautelares de la CIDH, refiere a que las mismas constituyen un elemento efectivo para el control Estatal por parte de la Comisión. Que estas se han vuelto mecanismos de presión negativa e inclusive intimidación a Gobiernos democráticamente electos so pretexto de la defensa de Derechos Humanos, tras la cual se esconden intereses políticos y empresariales principalmente dominados por los Estados Unidos. El Estado ecuatoriano, a través del Canciller Ricardo Patiño, ha expresado su disconformidad con las extralimitaciones en las que ha incurrido la Comisión a través de estas medidas, juzgando a los Estados y generando un clima de incomodidad y temerosidad. El Presidente ecuatoriano Rafael Correa se ha mostrado profundamente incómodo con estas medidas en virtud de que las mismas han sido "auto-atribuidas" por la Corte. Al tenor de las declaraciones del Mandatario,

En ninguna parte de la Convención que los países firmamos, se establece que la Comisión Interamericana puede emitir medidas cautelares. Solamente dice que los países pueden solicitarlas. (...) La Corte Interamericana es la única que puede emitir las medidas provisionales (Fundamedios, 2013).

Ante este escenario, Ecuador ha planteado públicamente una reforma al Artículo 25 de la Comisión, contenedor de la cláusula sobre medidas cautelares, en el sentido de limitar y especificar los casos en los cuales se pueda ejercer dicha facultad.

Existe un evidente temor por parte del estado Ecuatoriano a ser observado y a reconocer mecanismos que faculten y viabilicen, efectivamente, dicha observancia. Es recurrente el hecho de que muchos dispositivos jurídicos para la defensa de los Derechos Humanos tienden a ser demorosos, protocolarios, plagados de burocracia y, en cierta medida, inefectivos. En este sentido las medidas cautelares se han constituido como uno de los mecanismos de mayor uso y efectividad en la tutela de Derechos Humanos, accionado en el marco de la CIDH. Sin perjuicio de aquello es uno de los instrumentos jurídicos que se enfrenta directamente con el poder político y sus intereses localistas, electorales y personales, evidenciando el núcleo del problema, el dilema perpetuo entre el legitimado democrático, Estado, en detrimento de las pretensiones y derechos individuales.

Por las razones anteriormente expuestas, el Estado ecuatoriano ha mostrado públicamente su intención de reformar el reglamento de la CIDH en varios sentidos: (a) Delimitar la facultad de la Comisión para ejercer medidas cautelares; (b) Reubicar su sede y (c) Revisar los presupuestos financieros de la relatorías y precautelar que exista una proporcionalidad inter-partes (Sospedra, 2011). En caso de que estas pretensiones no tengan el eco ni la audiencia esperada, el Estado ecuatoriano 
se ha pronunciado vigorosamente en su voluntad de denunciar la Convención Americana de Derechos Humanos.

Sin desmerecer los argumentos jurídicos que Ecuador pueda tener a su haber, y en desconocimiento de aquellos, me permito advertir la imposibilidad de la amenaza ecuatoriana. En nuestro país, los tratados internacionales en materia de Derechos $\mathrm{Hu}-$ manos se encuentran, jerárquicamente, por sobre la Constitución, siempre que contengan condiciones más favorables para el ciudadano, en virtud del principio pro homine. Es decir, en Ecuador un tratado internacional, como lo es la $\mathrm{CADH}$, tiene rango constitucional empero pertenece, intrínsecamente, a la Constitución como texto integral aunque no se encuentre adherido formalmente a su cuerpo. A este concepto lo llamamos Bloque de Constitucionalidad.

Para entender esta teoría, es necesario tomar en cuenta que la Carta Magna es la médula espinal de todo el ordenamiento jurídico en el territorio ecuatoriano, pues a partir de sus principios y preceptos se desprenden las normas inferiores. Es la llamada norma fundante, el cuerpo legal primordial. El Estado ecuatoriano ha tenido una cierta tradición de firma y ratificación a un cúmulo de tratados internacionales que lo obligan a adecuar su normativa interna y procurar su aplicación directa e irrestricta; esto es posible a través de la configuración del mencionado Bloque de Constitucionalidad. Para efectos de entender el concepto a mayor profundidad La Corte Constitucional Colombiana lo define como,

Aquel conformado por normas y principios que, sin aparecer formalmente en el articulado del texto constitucional, son utilizados como parámetros del control de constitucionalidad de las leyes, por cuanto han sido normativamente integrados a la Constitución, por diversas vías y por mandato de la propia Constitución. Son pues verdaderos principios y reglas de valor constitucional, esto es, son normas situadas en el nivel constitucional, a pesar de que puedan a veces contener mecanismos de reforma diversos al de las normas del articulado constitucional strictu sensu (Bloque de Constitucionalidad - Concepto, 2003).

Con estos antecedentes postulamos la teoría de que la Convención Americana de Derechos Humanos (CADH) se encuentra plenamente adherida al Bloque de Constitucionalidad ecuatoriano, ergo, su denuncia equivale a una reforma constitucional propiamente dicha, debido a que desmiembra un elemento fundamental de los principios y normas rectoras, en materia de Derechos Humanos, que se encuentran presentes en el texto Constitucional aun sin estar expresamente manifiestas en el cuerpo legal.

De esta manera llegamos al campo de la reforma constitucional, campo recurrido por los políticos que observan la adecuación de la constitución a sus necesidades políticas como un imperativo para la gobernanza, olvidando el carácter supremo y fundante de la Constitución. En caso de que el Estado Ecuatoriano decida denunciar la $\mathrm{CADH}$, procedería una acción ante la Corte Constitucional en virtud de elevar dicha denuncia a una reforma constitucional, misma que solo puede darse mediante referéndum o a través de la Asamblea Nacional, según lo describe el artículo 441 de la Constitución. Es decir, en caso de que procediera una denuncia a la $\mathrm{CADH}$, los ecuatorianos tendríamos que ir a las urnas a ratificar esta decisión Estatal.

Sin prejuicio de lo mencionado anteriormente y, a riesgo de caer en la contradicción, deseo ser enfático en que una potencial denuncia a la CADH es improcedente, por ser inconstitucional. El Artículo 441, de la Constitución ecuatoriana menciona que,

La enmienda de uno o varios artículos de la Constitución que no altere su estructura fundamental, o el carácter y elementos constitutivos del Estado, que no establezca restricciones a los derechos y garantías, o que no modifique el procedimiento de reforma de la Constitución, se realizará (...) (Constitución de la República del Ecuador).

Es claro que nuestra norma invoca la irretroactividad e intangibilidad de los Derechos Humanos. Una vez que el Estado ha reconocido un mecanismo para su promoción o defensa -caso concreto la $\mathrm{CADH}$ - es inviable que se retracte, pues la Constitución establece un 'Candado Constitucional' que imposibilita la realización de reformas en cuanto tengan relación con la estructura fundamental de la Constitución, fundada en el Garantismo de Derechos, y que modifiquen o restrinjan derechos y garantías, lo que evidentemente sucedería en una eventual denuncia a la $\mathrm{CADH}$ por parte del Estado Ecuatoriano.

La protección y promoción de los Derechos Humanos debe ser perseguida con todos los medios y mecanismos posibles, aun cuando la historia ha comprobado que estos no siempre son cordiales con el poder. Es muy probable que los argumentos de derecho aquí expuestos no sean observados al momento de tomar una decisión política. Los intereses políticos no siempre convienen en el derecho positivo, pero la labor del ciudadano debe propender hacia la vigilancia de este estrecho vínculo entre el derecho y la política. Dentro del diálogo entre estos dos mundos se encuentran tangibles derechos, valores jurídicos, bienes y sobre todo una profunda identidad, de cierto modo imaginaria, que nos compete proteger.

\section{Referencias}

Bloque de Constitucionalidad - Concepto, Sentencia C-067/03 (Corte Constitucional de Colombia 2003).

Caballero, G. \& Anzola, M. (1995). Teoría Constitucional. Santa Fe de Bogotá: Editorial Temis.

Constitución de la República del Ecuador (2008).

Correa, R. (2008). Medidas cautelares ante la jurisdicción administrativa en Colombia. Seminario Internacional: reforma a la jurisdicción contenciosa administrativa. Memorias. (págs. 145-159). Bogotá.

Dueñas, O. (2008). Lecciones de Teoría Constitucional. Segunda ed. Bogotá: Librería Ediciones del Profesional.

Fundamedios. (12 de Marzo de 2013). Polémico debate por medidas cautelares. Recuperado el 2014, de Fundamedios: http://www.fundamedios.org.ec/autorregulacion-internacionales/articulos/polemico-debate-por-medidas-cautelares

Guzmán, M. (2010). Los Derechos Humanos. Quito: Prodedim. 
Jiménez, J. (1999). Derechos fundamentales: concepto y garantías, Madrid, Trotta, 1999. Recuperado de Boletín Mexicano de Derecho Comparado: http://www.juridicas.unam. mx/publica/rev/boletin/cont/127/art/art1.htm\#N17

Medidas Cautelares. (s.f.). Recuperado el 5 de Enero de 2014, de Organización de Estados Americanos: http://www.oas. org/es/cidh/decisiones/cautelares.asp

Pérez, A. (2006). La tercera generación de derechos humanos. Navarra, Thomson-Aranzadi. Recuperado de Boletín Mexicano de Derecho Comparado: http://www.juridicas.unam. $\mathrm{mx} /$ publica/rev/boletin/cont/127/art/art1.htm\#N17

Programa de Naciones Unidas para el Desarrollo (PNUD) (1997). La aplicación de los Tratados Internacionales sobre Derechos Humanos por los Tribunales Locales. Buenos Aires: Editores del Puerto.

Rolla, G. (s.f.). La concepción de los derechos fundamentales en el constitucionalismo latinoamericano. Universidad de Génova. Recuperado de: http://www.crdc.unige.it/docs/articles/Rolla3.pdf

Sospedra, F. (2011). Justicia Constitucional y Procesos Constitucionales. Pamplona: Editorial Civitas. 